Omni-Akuatika, 14 (2) : 59-65, 2018
ISSN: 1858-3873 print / 2476-9347 online
Research Article
journal homepage: http://ojs.omniaquatika.net

\title{
Nutrition of Edible Seaweed Kappaphycus alvarezii Related to Difefferent Environmental Coastal Water Condition
}

\author{
Eko Nurcahya Dewi ${ }^{1 *}$, Darmanto ${ }^{1}$, Ambariyanto $^{1}$ \\ ${ }^{1}$ Faculty Fisheries and Marine Sciences, Diponegoro University, Semarang 50275, Central Java, Indonesia
}

"Corresponding author: nurdewisatsmoko@yahoo.com

\begin{abstract}
Edible seaweed K. alvarezii collected from different coastal waters in Indonesia (Morowali and Teluk Ekas). The seaweed was extracted into semirefined carrageenan and it was determined on their nutrition quality. The results showed that the essential amino acids content of the three different samples SRC were similar as follows: aspartic acid, glutamic acid, serine, glysine, arginine, alanine, tyrosine, methionine, valine, phenylalanine, isoleucine, leucine and lysine. The gel strength $\left(\mathrm{g} / \mathrm{cm}^{2}\right)$ and viscosities value in Morowali, Ekas coastal waters and commercial SRC were different in the samples. FTIR spectroscopy determined that molecular present in three samples were kappa carrageenan.
\end{abstract}

Keywords: K. alvarezii, different water environmental, nutrition

\section{Introduction}

As people have become increasingly concerned about food safety, it is critical for seaweed farmers and manufacturers in the food supply chain to ensure seaweed harvesting quality. Seaweed extract, such as carrageenan agar, carrageenan and alginate, is valuable source of phycocolloids; furthermore, they are rich in protein, fiber, vitamin, and polyunsaturated fatty acids. Thus, they have been recognised as beneficial for human. Nowadays $K$. alvarezii is one of the important seaweed species cultivation developed sharply in the world (Buschmann et al., 2017). The increase on the high demand and the need on carrageenan in the extensive global industry is due to its uses as stabilizer, gelling agent, thickener, binder and additive for various dairy products, cosmetic, meat processing and pet food. Semi refined carrageenan (SRC) is one type of natural extracts from red algae that can be used as dried form and it can add distinctive flavor and nutritional value to healthy dishes. The characteristics of carrageenan are related to their physicochemical properties in global market,such as gelling capacity and viscosity which are important for improvement of functional properties in food (Silkin et al.,2012).

Indonesia is a potential area of seaweed cultivation in tropical region where
$60 \%$ of the tropical regions are potential for developing the seaweed cultivation; however, the potential coastal water that is used is less than $10 \%$ (Ministry of Marine Affairs and Fisheries, 2013). The coastal waters that are potential for developing seaweed include Central Sulawesi, South Sulawesi, Mollucas, West Nusa Tenggara and North Jawa Sea. The environmental condition has not optimally supported the development of the seaweed culture although the seaweed productions are quite potential. K. alvarezii can be cultivated using several methods, which are off-bottom and rafts or floating using long lines methods. The photosynthesis on the seaweed is affected by the existence of sunlight as the energy source and $\mathrm{CO} 2$ as the carbon source. The seaweed development also depends on the mineral source, which will affect the developmemt of seaweed thallus that will further determine the quality of the gel.

Most researches focused on quality product SRC and its application (Manuhara et al., 2016; Setyorini and Nurcahyani, 2016); however, research on their environmental quality in correlation with their nutrition quality product is still limited. Researchers also focus on the relationship between environmental parameter and the seaweed growth. On the other hand, research that examined some nutritional and physicochemical properties 
which are affected by different environmental condition is not available since less detailed mapping for potential area of seaweed cultivation has not been conducted yet (Benjama and Masniyom. 2011).

The objectives of this research are to evaluate the quality of the SRC from seaweed K.alvarezii which were harvested in different coastal water with different environmental conditions on nutritional, physical and chemical quality. The knowledge of quality seaweed can help plan a productive coastal area for seaweed culture with high quality. Furthermore, it can also be considered as a decision to farm or not to farm seaweed on the coastal water area.

\section{Materials and Methods}

\section{Sampling site}

The seaweed samples were cultured using floating monoline method and collected from Morowali coastal water (Central Sulawesi) and Teluk Ekas (West Nusa Tenggara).

\section{Extraction of Seaweed}

SRC from $\mathrm{K}$ alvarezii was processed was as follows: dried seaweed was boiled at $80^{\circ} \mathrm{C}$ in an $\mathrm{KOH}$ solution for 4 hours. Seaweed was then neutralized, chopped, dried, and grounded to a fine powder using a mill $(0,6 \mathrm{~mm}$ mesh size sieve).

\section{Methods of Quality Parameter Analysis}

The chemical compositions (protein, ash, and moisture contents), dietary fiber carbohydrate by difference and crude fiber of the SRC were determined according to the standard method (AOAC, 2005). The water enviromental samples are taken $30 \mathrm{~cm}$ under the water surface and then were determined by argentometric methods using an electronic multimeter and a refractometer. Nitrates (NO2) were tested using Saltwater Master Test kit.

Amino acids contained in samples were determined by high-performance liquid chromatography (HPLC) of o-pthaldialdehyde (OPA) derivatives as described in Benson and Hare (1975). Methanol and Mercaptoethanol solvent were applied as the mobile phase. The detector flourescence was Shimadzu RF-138 (Kyoto, Japan). The excitation wavelength of: $360 \mathrm{~nm}$, and an emission wavelength of : $460 \mathrm{~nm}$.

Pottssium bromide $(\mathrm{KBr})$ with an approximatelly $2 \mathrm{mg}$ SRC powder was homogenated,filled and then compressed into a thin pellet $1 \mathrm{~cm}$ in diameter.The results were recorded using FTIR spectrophotometer (Prestige- 21).

Gel strengths measurement were prepared by weighing 1,5\% SCR powder and diluted in $0,2 \%$ hot aquaeous $\mathrm{KCl}$ solution. It was then kept in the refrigerator temperature overnight. The gel strength was measured using TA-XT Plus Texture Analyzer. As comparison, SRC quality measurement was also performed on a commercially exported SRC. The determination of the viscosities solutions ( $3 \mathrm{~g}$ sample of SRC in $250 \mathrm{ml}$ aquadest) was measured with a Brookfield DV-E viscometer at $25^{\circ} \mathrm{C}$. Sulphate content was analysed using the method of sulphate hydrolysis followed by precipitation of sulphate as barium sulphate (AOAC, 2005).

Data of gel strength, viscosity and sulphate content were tested using ANOVA and if there is any significant different in treatment, analysis was continued using HSD test. The FTIR described spectra band on the different samples.

\section{Results and Disscusions}

\section{Nutritional composition analysis}

Figure 1 showed the chemical nutritional valueanalysed (dry bases) of different SRCs product that was processed from different environmental water sources. The SRCs showed variation in the nutrient content which were related to environmental parameters where seaweed growth. The nutritional composition can be influenced by the growing parameters (water temperature, salinity, light and nitrate as a nutrient compound), since macroalgae can be considered bioreactor that may able to provide different polysaccharides at different quantity.

The different amount of amonia and nitrate in the waters will result in the different proximate composition of macro algae. Generally, the high protein composition will reduce the carbohydrate composition in the forms of starch or dietary fiber. The effect on carbohydrate composition is not clearly understood but might be an interesting way to manipulate carbohydrate content and composition in algae. In floating long line net bag farming of K.alvarezii had a profound impact on the seed stocking and continuous cultivation since the available of ammonia and nitrate on the environmental water (Selvavinayagam and Dharmar, 2016).

The protein content as well as lipid content was present in small amount approximately $\quad 0,938-1,637 \%$, lipid 0,733$2,081 \%$, however this product consist of dietary 
fiber and its comprise nearly half of crude fiber. The lower content of lipid was probably due to the fact that source of energy on seaweed was on carbohydrate rather than lipid. Although it reported lipid is present in small amount range 1 to $5 \%$, however it is rich of fatty acids content (Rajasulochana et al.,2012).

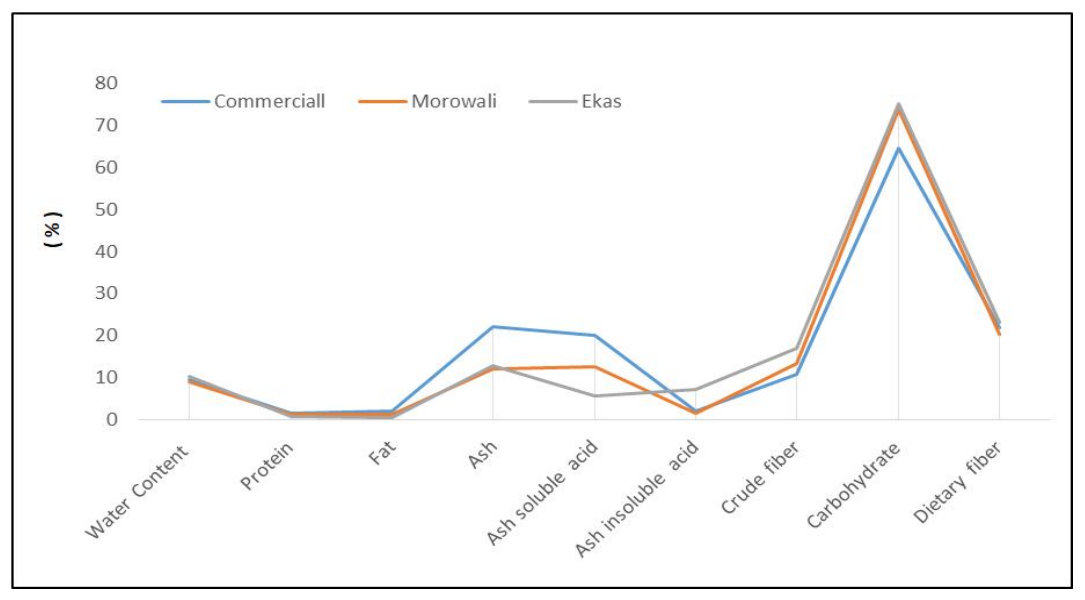

Figure 1. Nutritional Composition of Different SRC (\%)

\section{Amino Acid compositions}

All SCR samples showed similar 13 amino acids compound of: aspartic acid, glutamic acid, serine, glysine, arginine, alanine, tyrosine, methionine, valine, phenyalanine, isoleucine, leucine and lysine, in which aspartic and glutamic acids constituted together a large portion of the amino acids fraction $(29,05-34,24 \%)$.

It can be seen from Figure 2 that Morowali product has larger amount of all amino acid type in comparison with to others samples. Arginine is an essensial amino acid that can be found on second large amound of all SRC samples besides aspartate and glutamic acids. These results differ with previous research by Benjama and Masniyom (2011) on the brown algae (U.pertusa and U.intestinalis). They found that leucsine amino acid has the second large quantity on those spesies. These results also differ with result from Matanjun et al.. (2009), where lysine could not befound $E$. cottonii and $C$. lentiferra samples. The amino acids compound on dried powder of $K$ alvarezii was also differ with Rajasulochana et al.,2012 in which lysine is the major constituent and followed by asparagines, histidine, isoleucine, phenylalamine, tryptophan. These differences could be attributed to the exraction methods, species origin or place of cultured and seasonal time (Kotiya et al., 2011).

The results in Manivannan et al., (2009), who worked in India coastal found differences with this research on amino acid limiting factors. The nitrate and salinity (Table 1) content provides evidence that the compound supporting the development of amino acid, probably the higher nitrate may result in higher amount of amino acid content.

The present study agreed with research were done by Benjama and Masniyom (2011); who found that almost all seaweed contain a large amount of aspartate and glutamic acids component of amino acid. Amino acid compound can be reached from 22 to 24 on brown algae, 26 to $32 \%$ on the green algae. The amino acid essensial (EAAs) found on K.alvarezii were methionine, leucine, isoleusine, lysine, phenilalanin, tyrosin, arginine and valin, while Non-EAAs were aspartic acid, glutamic acid, serine, glycine and alanine. 


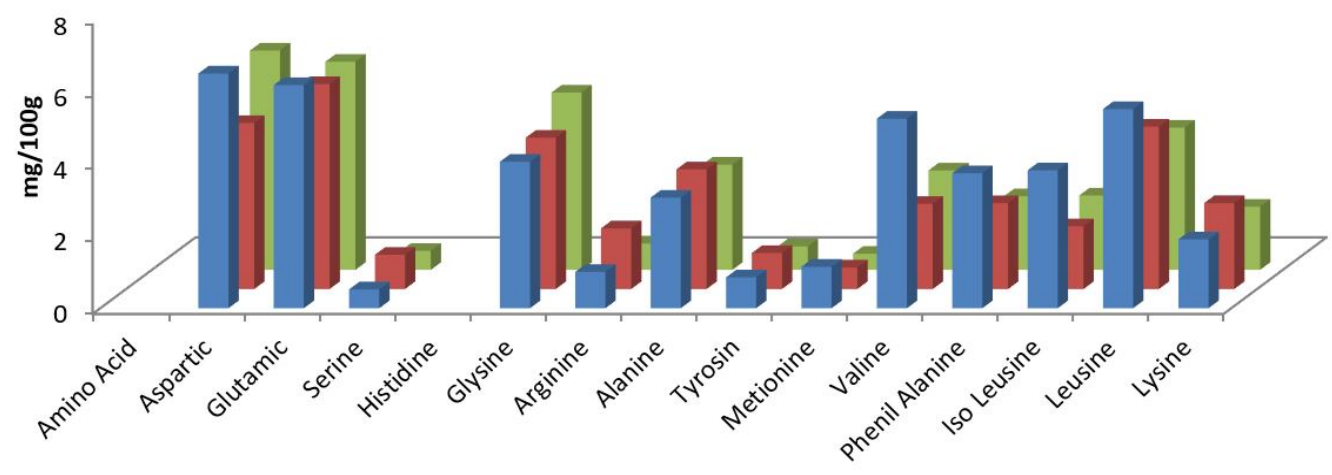

Figure 2. Amino acid content of Semi refined carrageenan ( $\mathrm{mgr} / 100 \mathrm{~g})$ samples

\section{FTIR spectroscopy testing}

FTIR patern on spectroscopy testing showed that the molecular that was present in two different SRC and commercial samples were quite identical. All sampels showed 3,6anhydrogalactose content as an characteristic of red algae (Gomez and Ruperes, 2011).

These result showed that the spectra band of $1257,59 \mathrm{~cm}^{-1}$ which was indicated to ester sulphate, $933,55 \mathrm{~cm}^{-1}$ for 3,6 anhydrogalactose where $848,68 \mathrm{~cm}^{-1}$ represented that galactosa-4-sulphate was present .
Another functional group such as amines (-NH2), alcohols (-OH) and carboxyl ($\mathrm{C}=\mathrm{O}$ ) groups (Kiruba et al., 2015) were also appeared in this research. Some wavenumber region were observed such as methyl (1370 $\left.1375 \mathrm{~cm}^{-1}\right)$; ester sulphate $\left(1210-1260 \mathrm{~cm}^{-1}\right)$; glycosidic bound (1010- $1080 \mathrm{~cm}^{-1}$ ), 840-850 $\mathrm{cm}^{-}$(galactose-4 sulphate); 810-820 $\mathrm{cm}^{-1}$ (galactose-6-sulphate); $800-805 \quad \mathrm{~cm}^{-1} \quad(3,6$ anhydrogalactose-2 sulphate). Based on the spectra bands on wavenumber region samples, those SRCs can be identified as a kappa carrageenan (Gomez and Ruperes, 2011, Kiruba et al., 2015 and Manuhara et al., 2016). 


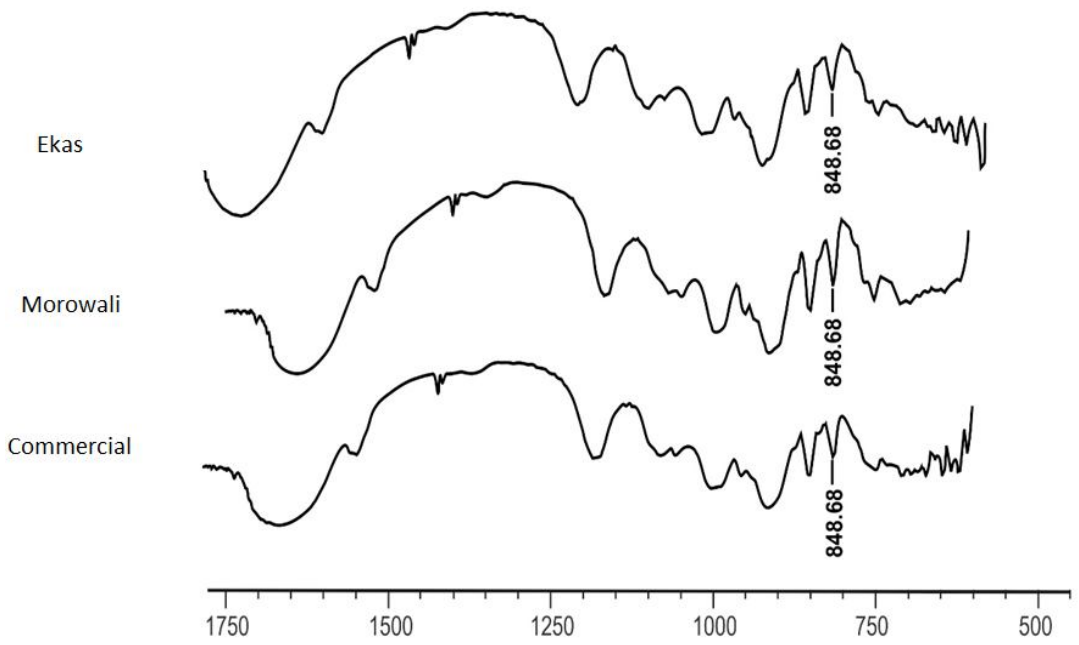

Figure 3. FTIR spectroscopy of SRC $/ \mathrm{cm}^{-1}$

Physicochemical analysis

The ANOVA test of gel strength for different coastal water location showed a highly significant influenced, and the highest was recorded in Morowali. All the samples gel strength were lower than the commercial sample. The gel was higher in comparison to the gel strength Karimun Jawa island carrageenan which was only $152,29 \mathrm{~g} . \mathrm{cm}^{2}$ (Manuhara et al., 2016).
The samples viscosities showed that there were no significant differences between samples. There was a negative correlation between gel strength and sulphate content, where the decreasing sulphate content will increase gel strength. On the contrary increasing gel strength followed by and increasing in viscocity.

Table 1. Gel Strength, Viscosity, Sulphate Content Of SRC and Water Quality Conditions of Different Coastal Water

\begin{tabular}{lccc}
\hline \multirow{2}{*}{ SRC Specification } & \multicolumn{3}{c}{ Samples of } \\
\cline { 2 - 4 } & MorowaliCoastal Water & EkasCoastal Water & Commercial \\
\hline Physical Characteristic & & & \\
- $\quad$ Gel Strength $\left(\mathrm{g} / \mathrm{cm}^{-2}\right)$ & $323,939 \pm 2,894$ & $317,570 \pm 1,292$ & $441^{*}$ \\
- Viscosity $(\mathrm{cPs})$ & $23,375 \pm 0,099$ & $21,803 \pm 0,109$ & $25,0^{*}$ \\
- & $5,331 \pm 0,007$ & $6,882 \pm 0,121$ & 5,513 \\
Wulphate/SO4$(\%)$ & & & \\
Water Quality & & & \\
- Salinity $(\% / \mathrm{oo})$ & $34,55 \pm 0,494$ & $34,55 \pm 0,494$ & \\
- Nitrate (mg/gram) & $1,46 \pm 0,07$ & $1,09 \pm 1,35$ & \\
- Temperature $\left({ }^{\circ} \mathrm{C}\right)$ & 30,30 to 33,70 & 26,0 to 30,80 & \\
- Dissolved oxygen (ppm) & 7,10 to 9,83 & 7,85 to 8,45 & \\
\hline
\end{tabular}

*Note : * - data information on SRC commercial packaging

- data presented in the table was done in three replicates

Table 1 showed there was an inverse correlationship between gel strength and sulphate content, where the increased gel strength would decrease the sulphate content. On the contrary, increasing gel strength followed by an increasing viscocity due to macromoleculs compound on gel strength is getting higher on weight.

Gels strength quality were affected by the growth of hydrocolloid compound in the thallus, where the growths of thallus were influenced by nitrates compound. Nitrates were carried into the thallus cells by the use of nitrate reductase and was transformed into nitrites (Praiboonet al., 2006; Silkin et al.,2012). The growth rate can change considerably depending on the amount of nitrates in water. Where limited, the growth activity of thallus was stopped and increased gradually, hence it was designed as polynomial 
function. Gel strength of carrageenan was high when nitrogen content was high and vice versa. A clear pattern of variation was observed for the relation of sulphate content and gel strength. The gel strength of both two sampels were lower than the value obtained from the commercial sample.

However, the gel strength of SRC from 2 different coastal water in Indonesia, were lower in comparison to those gel strength from reported by Hayashi et al., (2007) on their research using K.alvarezii at Sao Paulo State, Brazil. It were also lower to those has been done by Periyasamy et al.,2015 at Tamil Nadu Southeast coast of India where gel strength were varied to $379.05 \pm 6.0$ to $486.44 \pm 5.57 \mathrm{~g} \mathrm{~cm}^{-2}$. The differences could be resulted from the different methods of extraction. Some of samples were extracted using different standard of extraction in which carrageenan sample already purified on alcohol solution. The gel strength and viscosity could be increased when the factors of water quality such as seawater temperature, salinity, and nitrate increased. (Jayasinghe et al., 2016).

\section{Conclusions}

All SRC sampels showed similar amino acid of: aspartic acid, glutamic acid, serine, glysine, arginine, alanine, tyrosine ,methionine, valine, phenyalanine, isoleucine, leucine and lysine.

The gel strength and viscosity were different as their water quality such as salinity and nitrate. FTIR spectroscopy determined that molecular present in three samples were kappa carrageenan.

\section{Acknowledgment;}

This work was made possible by the financial support of Fisheries and Marine Sciences Faculty of Diponegoro University Semarang Indonesia,2015.

\section{References}

AOAC. 2005. Official Methods of Analysis . Association of Official Analytical Chemists, Arlington. VA.

Benjama, O.,Masniyom. P. 2011. Nutritional Composition and Physicochemical Properties of two Green seaweeds $(U$. Ivapertusa and $U$. ilntestinales) from the Pattani Bay in Southern Thailand. Sonklanakarin. J.Sci.Technol. 33 (5) : 575-583.
Benson, J.R., Hare, P.R. $1975 . \quad$ OPhthalaldehyde: Fluorogenic Detection of Primary Amines in the Picomole Range. Comparison with Fluoresence and Ninhydrin, Proc.Nat Acad.Sci.,72 (2): 619-622.

Buschmann,A.J.,Camus,C., Infante,J.,Neori,A., Israel,A., Hernández-González, M., Pereda,S., Gomez Pinchetti, J,L., Golberg, A., Shalev., N., Critchley, A. 2017. Seaweed production: overview of the global state of exploitation, farming and emerging research activity. European Journal of Phycology. 52 (4): 391-406.

Gomez, E.O., Ruperez P.2011.FTIR-ATR spectroscopy as a tool for polysaccharide identification in edible brown and red seaweeds. J Food Hydrocolloids 25 (6): 1514-1520

Hayashi, L., Edision J.P.,Fungyi C. 2007. Growth rate and carrageenan analyses in gour strain of $K$. alvarezii (Rhodophyta, Gigartinales) farmed in subtropical water Sao Paulo State, Brazil. J. Appl Phycol. 19 :393-399.

Jayasinghe, P.S., Pahalawattaarachchi, V., Ranaweera K.K.D.S. 2016. Effect of Extraction Methods on the yield and physiochemical properties of polysaccharides extracted from seaweed available in Sri Lanka. Poult Fish Wildl Sci. 4 (150) : 1-6

Kiruba. M., Pradeep A., S.Juliana J. 2015. Study of phytoconstituents and antibacterial activity of $K$. alvarezii. Int. J of Curr Microbiology. App Sciences 4(5):1209-1217.

Kotiya, A.S., Gunalan, P., H. V. Jatikumar, Dave T., Solanki. J. Nayan. P. M. 2011. Growth comparison of the seaweed K.alvarezii in nine different coastal areas of Gujarat coast, India. Advances in Applied Science Research, 2011, 2 (3):99-106.

Manivannan, G. Thirumaran, G. Karthika D, $P$, Anantharaman, T. Balasubramanian. 2009. Proximate composition of different group of seaweeds from Vedalai Coastal Waters (Gulf of Mannar): Southeast Coast of India. IDOSI Publications Middle-East Journal of Scientific Research 4 (2):72-77.

Manuhara, G.J., Praseptiangga, D. Riyanto R.A. 2016. Extraction and characterization of refined $\mathrm{K}$ carrageenan of Red Algae [K. alvarezii 
(Doty P.C. Silva, 1996)] originated from KarimunJawa Islands. Aquatic Procedia $7: 106-111$.

Matanjun, P., Mohamed, S., Mustapha N., Muhammad. K. 2009. Nutrient content of tropical edible seaweeds, $E$. cottonii, C. Lentillifera and $S$. polycystum. J. Appl Phycol 21: 75 81.

Ministry of Marine Affairs and Fisheries, 2013. Profil of business and investment opportunities on seaweed Industry in Indonesia III.

Periyasamy, C., Subba R, P.V., Anantharaman P.2016. Spatial and temporal variation in carrageenan yield and gel strength of cultivated $K$. alvarezii (Doty) in relation to environmental parameters in Palk Bay waters, Tamil Nadu, Southeast coast of India.J Appl Phycol. 28 (1): 525532.

Praiboon, J.,Chirapat, A;Akakabe, Y; Bhumibhamon, O. Kajiwara, T. 2006. Physical andchemical characterization of agar polysaccharides extracted from the Thai and Japanese species of Gracilaria. Science Asia Supplement 1: 11-17.
Rajasulochana, P., Krishnamoorthy, P., Dhamotharan. R. 2012. Potential Application of $K$. alvareziin agricultural and pharmaceutical industry. J. of Chemical and Pharmaceutical Research $4(1): 33-37$

Selvavinayagam K.T., Dharmar K. 2016. Selection of potential method for cultivation and seed stock maintenance of $K$. alvarezii during the northeast monsoon in southeast coast of India.J of Appl Phycol. $28: 1-12$

Setyorini, D., Nurcahyani, P,R. 2016. Effect of addition of semi refined carrageenan on mechanical characteristics of gum arabic edible film. IOP Conf. Series: Materials Science and Engineering. 128:1-7.

Silkin, V.A.,Dzizurov, Chasovnikov., Esin,N.I. 2012. Modelling Nitrate Uptake and Nitrite Release by Seaweed. International Journal on Algae 14(2):185200.

Steel, R. G. B., Torrie. J.H 1991.Principle and Statistic Procedure Second Edition. Gramedia Pustaka Utama. Jakarta, 327 pp. 